\title{
Can donepezil hydrochloride reduce the role of neuroleptic drugs in delirium? A case report
}

\author{
Lloyd D. Hughes', Emily McKay² \\ ${ }^{1} 4$ th year medical student, University of Dundee Medical School, Dundee, United Kingdom \\ ${ }^{2}$ Senior Charge Nurse, Southern Cross Healthcare, Dundee Base, United Kingdom \\ *Corresponding author: Lloyd D. Hughes; L.D.Hughes@dundee.ac.uk
}

\begin{abstract}
Background: Recent evidence shows that a confirmed diagnosis of delirium increases both patient morbidity and mortality. Importantly, these increases are independent of patient age, and presence of co-morbid disease. In the last few years, there has been evidence that acetylcholinesterase inhibitors may have a limited role in managing episodes of mild/moderate delirium.

Methods: This case study reports a patient whose behavioral disturbances caused by delirium, responded well to donepezil hydrochloride in a nursing home in Dundee, United Kingdom.

Results: Our clinical case focuses on a patient who was diagnosed with a mixed picture delirium after developing PUO. This case report notes that $\mathrm{Mr}$ A, a patient already prescribed donepezil hydrochloride, saw an improvement in his behavioral symptoms after an increase in his dose. This enabled the patient to avoid receiving neuroleptic or benzodiazepine medication, known to be particularly problematic in older patients.

Conclusion: The authors tentatively propose that patients in community care already prescribed acetylcholinesterase inhibitors, may benefit from an increased dose in cases of mild delirium (where there is no clear cause or requirement for hospital admission). In line with the significant impact that delirium has upon older patients in community care, we would call for further studies looking at the influence that these medications may have on the sequelae of delirium in patients in the community.
\end{abstract}

Keywords: geriatrics; delirium; psychiatry; acetylcholinesterase inhibitors.

\section{INTRODUCTION}

D elirium is the term used to describe a state of fluctuating organic mental confusion, usually of abrupt onset and relatively short duration. ${ }^{1,2}$ It results in impaired attention and concentration, impaired consciousness, disordered perception, visual hallucinations, and autonomic features, such as sweating and tachycardia. ${ }^{3,4}$ This condition is relatively common in older patients, with up to $56 \%$ of hospitalized geriatric patients developing delirium during their hospital stay. ${ }^{5}$ Furthermore, a Dutch study of 3,627 residents noted that the prevalence of delirium in nursing and residential homes is $8.9 \%$ and $8.2 \%$, respectively. ${ }^{6}$ There are three types of delirium: hypoactive, hyperactive, and mixed (see Table 1). ${ }^{1-4,7-9}$

The general principles involved in the treatment of delirium include:

- treating any precipitating cause such as infection, dehydration, or hypoxia;

- optimizing the patient's environment (e.g. provision of ambient lighting);

- judicious use of psychotropic drugs, such as low-dose haloperidol, to manage particularly distressing behavioral disturbances. ${ }^{1-4,7-9}$
Interestingly, the neurotransmitter acetylcholine (Ach) has been implicated in delirium and, consequently, acetylcholinesterase inhibitors may have a role in managing some episodes of mild/moderate delirium. ${ }^{10}$ This case study reports a patient with behavioral disturbances caused by delirium (secondary to pyrexia of unknown origin [PUO]) who responded well to donepezil hydrochloride (donepezil $\mathrm{HCl}$ ), an acetylcholinesterase inhibitor, in a nursing home in Dundee, United Kingdom. The current evidence regarding the role acetylcholinesterase inhibitors may play in delirium will subsequently be discussed.

Increasing the dose of donepezil $\mathrm{HCl}$ is a novel clinical approach to managing behavioral disturbances in delirium. This change in the patient's treatment plan, alongside rationalizing his prescribed medications, and non-drug methods of delirium management, led to rapid patient recovery. Avoiding antibiotic prescription in patients with PUO and an inconclusive clinical picture of infection is important, particularly in nursing homes, to avoid antibiotic resistance and side-effects. This case study suggests that it may be prudent for clinicians who are asked to review patients with good baseline function who have developed a mild delirium with 
Table 1. Description of the three forms of delirium. ${ }^{7-9}$

Hyperactive delirium (30\%):

Patients become agitated and hyper-alert. Hyperactive delirium is associated with repetitive behaviors, wandering, hallucinations, and verbal/physical aggression.

Hypoactive delirium (25\%):

Patients become quiet and withdrawn. It is important to consider depression as a differential diagnosis in such cases.

Mixed delirium (45\%):

Patients have a fluctuating pattern of both hyperactive and hypoactive symptoms.

behavioral disturbance in a nursing home to avoid generic antibiotic prescription and consider if an increased dose of an acetylcholinesterase inhibitor may be of benefit (if already prescribed).

\section{CASE STUDY}

\section{History}

This case discusses an 86-year-old male (Mr. A), resident in a nursing home, who developed a mixed picture delirium after developing PUO.

\section{Day 1}

Nursing staff noted that Mr. A was reluctant to leave his bed (extremely unusual behavior for this particular patient). Mr. A became agitated when spoken to by clinical staff and became verbally and physically aggressive, which was also very unusual. His agitation brought on significant breathlessness (patient used accessory muscles and complained of 'feeling short of breath'). Importantly, Mr. A was not breathless at rest and when calm. After speaking to the previous night shift nursing team and reviewing patient records, Mr. A was noted to have been well up to the morning shift.

Mr. A had a past medical history of long-standing primary hypertension, angina pectoris, osteoporosis, and Alzheimer's disease, but generally kept in good health. Mr. A had not been treated for chest infection, urinary tract infection, or been diagnosed with delirium in the past. Prescribed medications included lisinopril $5 \mathrm{mg}$ (once daily), donepezil $\mathrm{HCl} 10 \mathrm{mg}$ (once daily), disodium etidronate $200 \mathrm{mg}$ (once daily), and, as required, glyceryl trinitrate. The patient had been prescribed donepezil $\mathrm{HCl}$ for a 10-month period (on 3-month review) and was allergic to amoxicillin.

Despite his considerable cognitive impairment, Mr. A normally engaged well with his family, nursing/care staff, and other residents. Mr. A maintained good mobility, using a walker to move around the home. Finally, there were no residents in the nursing home who had been diagnosed with an infection.

The nursing team called for the patient's general practitioner (GP) to arrange a visit later in the day and make a medical assessment.

\section{Clinical assessment}

Day 1

While waiting for the GP, nursing staff took some baseline physiological measurements, including blood pressure $(142 / 95 \mathrm{mmHg})$, heart rate $(87$ beats per minute), respiratory rate (26 breaths per minute when disturbed and 17 breaths per minute when quietly observed), and a tympanic temperature $\left(37.9^{\circ} \mathrm{C}\right)$.

Also, the care team carried out a confusion assessment method (CAM) and a mini-mental state examination (MMSE) to assess the patient's cognition. The MMSE is useful in establishing whether a patient has a degree of cognitive impairment and is used to chart cognitive changes both acutely and chronically. ${ }^{11}$ The MMSE assesses orientation in time and place, registration, attention and calculation, recall, language, repetition, and interpreting complex commands. ${ }^{12}$ An MMSE score of $\leq 23$ is the widely accepted and frequently used cutoff score in clinical practice. ${ }^{11,12}$ The CAM has been widely used in research ${ }^{4}$ and is a simple algorithm with four questions. ${ }^{4,13} \mathrm{~A}$ diagnosis of delirium requires the presence of both and two, in addition to either three or four (see Table 2).

Clinical assessment showed that the patient had a 7-point reduction on his MMSE (from 19 to 12) and was positive in all four CAM domains. In addition, abnormal psychomotor behavior was documented during these cognitive assessments, including episodes of physical aggression and restlessness.

A clinical examination carried out in the afternoon by the patient's GP failed to isolate a cause for the patient's pyrexia. The patient was recorded as having heart sounds $\mathrm{S} 1+\mathrm{S} 2$, a clear chest, a soft non-tender abdomen, and no obvious sign of discomfort when micturating. Vital signs were obtained again, and they showed the same clinical picture: continued pyrexia $\left(37.8^{\circ} \mathrm{C}\right)$ and tachypnea only when agitated ( 29 breaths per minute).

The patient had blood labs taken by the GP, including full blood count (FBC), C-reactive protein (CRP), liver function tests (LFT), and urea and electrolytes (U\&Es). Blood and urine cultures were sent for culture and sensitivity. In addition, the GP arranged for Mr. A to attend the local hospital the following morning to have a chest X-ray. 
Table 2. The confusion assessment method (CAM). ${ }^{4,13}$

1. Acute onset and fluctuating course: This feature is assessed by asking an informant.

- Is there evidence of a sudden change from the patient's previous mental state?

- Did the abnormal behavior tend to fluctuate through the day?

2. Inattention: This feature is assessed by asking an informant.

- Did the patients have difficulty focusing attention, were they easily distractible, or did they have difficulty keeping track of the conversation or what was happening?

3. Disorganized thinking: This feature is assessed by reviewing the patient.

- Was the patient's thinking disorganized, was their conversation rambling or incoherent, was there unpredictable switching from subject to subject?

4. Altered consciousness: This feature is assessed by reviewing the patient.

- Rate this patient's level of consciousness as alert [normal], vigilant [hyper alert], lethargic [drowsy, easily aroused], stuporose [hard to arouse], or comatose [unarousable].

It was felt at this time that a generic antibiotic prescription for PUO should be avoided, and the results of investigations should prompt anti-microbial therapy, if required. First, the patient was allergic to the first-line antibiotic that would be prescribed in this circumstance, according to the National Health Service Tayside guidelines. ${ }^{14,15}$ Second, this patient demography has a higher risk of side effects with antibiotics ${ }^{16,17}$ and, in this case, it was not clear whether the cause of the patient's delirium was in fact infective. Crucially, the patient was only breathless when agitated, so a care plan was developed to allow the patient to rest in his room and not be disturbed, unless clinically necessary.

\section{Day 2}

Shortly after having his chest X-ray taken, the patient became increasingly aggressive and uncooperative, making it difficult for nursing staff to ensure medication compliance. After a second GP review, the patient had his lisinopril and disodium etidronate stopped (short-term) and the dose of donepezil $\mathrm{HCl}$ increased to $10 \mathrm{mg}$ (twice daily) as a way of trying to improve his behavioral symptoms. Other psychotropic medications were avoided, in this instance, as a result of their side effects. ${ }^{18-20}$ Within 1 day of increasing the donepezil $\mathrm{HCl}$ dose, the patient's symptoms of aggression and agitation improved. This reduced his breathlessness as he was more relaxed in his environment. These behavioral improvements were not associated with any change in his recorded tympanic temperature (day $2=37.9^{\circ} \mathrm{C}$ ).

Investigation results were obtained by the evening of day 2, noting mildly elevated white cell count $\left(14.0 \times 10^{9} / \mathrm{L}\right)$ and CRP. ${ }^{12}$ Selected investigation results are noted in Table 3.

In line with the patient's clinical improvement and lack of a strong clinical picture for the presence of an infection, it was felt that antibiotics would not be required unless the he became unwell again. Within 3 days, the patient's MMSE score returned to 19 and CAM results no longer suggested delirium. The dose of donepezil $\mathrm{HCl}$ was reduced back to $10 \mathrm{mg}$ (once daily) after these improvements were documented.

\section{DISCUSSION}

Delirium is not a benign condition, with recent estimates placing mortality rates between 10 and $26 \% .^{21}$ In recent years, the neurotransmitter ACh has been implicated in the complex neurophysiological processes involved in delirium. ${ }^{10}$ ACh is an important neurotransmitter that is involved in the communication between nerve cells. ${ }^{11} \mathrm{ACh}$ has been shown to be associated with human sensory perception, memory, and attention. ${ }^{21,22}$ Since 1997, deficiency in ACh has been linked to some of the classic symptoms experienced by patients with Alzheimer's disease, such as memory loss. ${ }^{23,24}$

This 'cholinergic hypothesis' led to the development of acetylcholinesterase inhibitors. These medications prevent the activity of acetylcholinesterase, the enzyme responsible for breaking down $\mathrm{ACh}$ in the brain. Thus, these medications increase the concentration of Ach in the brain and have been shown to help symptoms of memory loss and slow the behavioral changes associated with Alzheimer's disease. ${ }^{11,25}$ There are three acetylcholinesterase inhibitors that are licensed for use in the United Kingdom, namely donepezil $\mathrm{HCl}$,

Table 3. Selected investigation results of Mr. A.

\begin{tabular}{ll}
\hline Investigation & Investigation result \\
\hline FBC & RBC $6.5 \times 10^{12} / \mathrm{L}$ \\
& WCC $14.0 \times 10^{9} / \mathrm{L}$ \\
& Platelets $190 \times 10^{9} / \mathrm{L}$ \\
CRP & 12 \\
U\&Es & Sodium $142 \mathrm{mmol} / \mathrm{L}$ \\
& Potassium $4.5 \mathrm{mmol} / \mathrm{L}$ \\
Blood culture and sensitivity & Urea $4.9 \mathrm{mmol} / \mathrm{L}$ \\
Urine culture and sensitivity & Negative growth \\
Chest X-ray & Negative growth \\
\hline
\end{tabular}


rivastigmine, and galantamine. ${ }^{11,26}$ These drugs can provide short- to medium-term improvements in patient memory symptoms. ${ }^{25}$

\section{ACh and delirium}

There have been suggestions that ACh deficiency may be the cause of some of the clinical hallmarks of delirium, such as impaired memory, perceptual abnormalities, and inattention. Studies of cholinesterase inhibitors in patients with delirium suggest that these medications could have a role in reducing both the frequency and the duration of delirium episodes ${ }^{27,28}$ and as a preoperative risk reducer for elderly patients undergoing elective surgery. ${ }^{29}$ Furthermore, low preoperative plasma cholinesterase activity may be able to predict the risk of postoperative delirium in elderly patients. ${ }^{30}$

The only double-blind randomized placebo-controlled trial looking at Ach inhibitors and delirium noted disappointing results. ${ }^{31}$ The study assessed the use of rivastigmine in critically ill patients admitted to the intensive care unit; however, the authors noted that rivastigmine did not decrease the duration of delirium and may have actually increased patient mortality, leading to halting of the study. ${ }^{31}$ There were some problems and concerns voiced about the trial, including the design of the study and subject selection, ${ }^{32,33}$ but these results have prompted fresh concerns about this treatment approach, especially in critically ill patients. Furthermore, almost one-third (29\%) of the patients cannot take these memory-enhancing drugs due to gastrointestinal side effects, such as nausea, vomiting, and diarrhea. ${ }^{25}$

\section{Clinical case}

Our clinical case focuses on an elderly male who was diagnosed with a mixed picture delirium after developing PUO. This case report notes that Mr. A, a patient already prescribed donepezil $\mathrm{HCl}$, had improvement in his behavioral symptoms after an increase in his dose. This meant that he would not be on neuroleptic or benzodiazepine medication, known to be particularly problematic in older patients. ${ }^{20}$

\section{LIMITATIONS}

Clearly, there are limitations to any case study as a method of influencing clinical practice. Indeed, we have drawn some tentative conclusions based on one patient experience. Furthermore, our conclusions are somewhat limited as Mr. A is not a typical resident in a nursing home. Mr. A was diagnosed with PUO (not confirmed infection), kept generally well, and had never been previously diagnosed with delirium. Therefore, we cannot extrapolate our findings to many other patients residing in nursing and care home settings. However, we do feel that this case suggests that further research is required to assess whether acetylcholinesterase inhibitors may have a role in managing specific patients with mild delirium.

\section{A magic bullet for delirium?}

It should be stressed that it is unlikely that a medication will ever be the sole treatment of delirium and replace good-quality nursing care and environmental adjustments (Table 4). ${ }^{35-37}$ Any medication will complement non-drug therapies to improve outcomes for patients.

This is because delirium has an extremely complex pathophysiology ${ }^{37}$ with cerebral inflammation, ${ }^{38}$ the sickness behavior response, ${ }^{38}$ and altered activity of the limbic-hypothalamic-pituitary-adrenal axis, ${ }^{38}$ all proposed as potential mechanisms. Furthermore, in addition to altered homeostasis of Ach, patients with delirium commonly have increased cortisol levels, ${ }^{37}$ altered serotonin levels, ${ }^{39,40}$ altered concentrations of amino acids (such as tryptophan and tyrosine), ${ }_{1}^{39,40}$ and decreased plasma glutamate levels. ${ }^{41}$ Crucially, it is most likely that patients with delirium will have a number of concurrent metabolic disturbances rather than just one. Thus, a single drug intervention may only help one aspect of a complex physiological process. However, if this can be

Table 4. Risk factors; common precipitants and general measures to avoid delirium. ${ }^{7,34-37}$

\begin{tabular}{lll}
\hline Risk factors & \multicolumn{1}{c}{ Common precipitants } & General measures to avoid delirium in patients \\
\hline $\begin{array}{l}\text { Increasing age } \\
\text { Polypharmacy }\end{array}$ & $\begin{array}{l}\text { Hypoxia } \\
\text { Metabolic and electrolyte } \\
\text { abnormalities } \\
\text { Infections }\end{array}$ & $\begin{array}{l}\text { Avoid unnecessary moving and transferring of patients } \\
\text { Avoid prescribing high-risk drugs, if at all possible (opioids, } \\
\text { benzodiazepines, barbiturates) } \\
\text { Surgery }\end{array}$ \\
$\begin{array}{l}\text { Substance abuse (alcohol, } \\
\text { illicit substances) }\end{array}$ & Alcohol or sedative withdrawal \\
$\begin{array}{l}\text { Postoperative states } \\
\text { CNS causes (structural, } \\
\text { infective, thrombotic) }\end{array}$ & $\begin{array}{l}\text { good oxygen supply and minimizing physiological stresses) } \\
\text { Orientation (familiar objects, continuity of nurses) }\end{array}$ \\
\end{tabular}


done using medications with a lower side effect profile to the current sedative medications, it would certainly be beneficial to clinical practice.

\section{CONCLUSION}

Delirium can be secondary to brain damage and to metabolic disturbances, with reduced levels of ACh potentially involved. This clinical case focused on a patient who was diagnosed with a mixed picture delirium after developing PUO. This case report notes that Mr. A, a patient already prescribed donepezil $\mathrm{HCl}$, had an improvement in his behavioral symptoms after an increase in his donepezil $\mathrm{HCl}$ dose.

The authors tentatively propose that patients in nursing homes already prescribed acetylcholinesterase inhibitors may benefit from an increased dose in cases of mild delirium (where there is no clear cause or requirement for hospital admission). In line with the significant impact that delirium has upon older patients in residential and nursing home care, we would call for further studies looking at the influence that these medications may have on the sequelae of delirium in patients in these environments.

\section{CONSENT}

Consent has been given for this case to be published and the consent form can be reviewed by the editor upon request.

Acknowledgements: LH would like to personally thank Professor Marion McMurdo (Professor of Geriatric Medicine) and Dr. Miles Witham (Consultant Geriatrician) for their valuable inputs and support into academic writing.

Conflict of interest and funding: Both authors have completed the Unified Competing Interest form at www.icmje.org/ coi_disclosure.pdf (available on request from the corresponding author) and declare that the study received no external funding and the authors have no financial conflicts of interest to report.

\section{REFERENCES}

1. Fields SD. 2003. Delirium predicts 12 -month mortality independent of dementia status. ACP J Club 139(3):80. 2. Alagiakrishnan K, Blanchette P. Delirium; 2012. Available from: http://emedicine.medscape.com/article/288890-overview [cited 28 October 2012].

3. Cerejeira J, Taylor JP. 2011. Diagnosing, treating and preventing delirium. Geriatr Med 41(2):81-5.

4. Curran S, Wattis J. 2007. Delirium and the elderly patient. Geriatr Med 37(11):35-40.

5. Inouye SK. 2006. Delirium in older persons. NEJM 345:

1157-65. http://dx.doi.org/10.1056/NEJMra052321.

6. Boorsma M, Joling KJ, Frijters DH, Ribbe ME, Nijpels G, van Hout JP. 2011. The prevalence, incidence and risk factors for delirium in Dutch nursing homes and residential care homes. Int J Geriatr Psychiatry 26(7):711-22. http://dx.doi.org/10.1002/gps.2770. 7. Hughes LD, Witham MD, MacLullich A. 2012. Delirium in older patients: important determinant of hospital outcome. J Indian Acad Geriatr 8(2):92-4.

8. Wass S, Webster PJ, Nair BR. 2008. Delirium in the elderly: a review. Oman Med J 23(3):150-7.

9. McCusker J, Cole M, Dendukuri N, Han L, Belzile E. 2003. The course of delirium in older medical inpatients: a prospective study. J Gen Intern Med 18:696704.

10. Tune LE, Egeli S. 1999. Acetylcholine and delirium. Dement Geriatr Cogn Disord 10(5):342-4. http://dx.doi.org/10.1159/000017167. 11. Hughes LD, Mthembu M, Adams L. 2011. Diagnostic workup and treatment of Dementia. Geriatr Med 41(11):595-600.

12. GP Training Website. Mini-mental state examination. Available from: http://www.gptraining.net/protocol/ psychiatry/mini_mental_state.htm [cited 28 October 2012]. 13. Waszynski CM. 2001. Confusion assessment method (CAM). Best practices in nursing care to older adults 13(11):1-2. 14. NHS Tayside Website. Tayside area formulary. Available from: http://www.nhstaysideadtc.scot.nhs.uk/TAPG\%20html/ MAIN/Front\%20page.htm [cited 28 October 2012].

15. National Institute for Health and Clinical Excellence (2010). Delirium: diagnosis, prevention and cure. London: National Institute for Health and Clinical Excellence.

16. Litvin CB, Ornstein SM, Wessell AM, Nemeth LS, Nietert PJ. 2012. Adoption of a clinical decision support system to promote judicious use of antibiotics for acute respiratory infections in primary care. Int J Med Inform 81(8):521-6. http://

dx.doi.org/10.1016/j.ijmedinf.2012.03.002.

17. Posner JD. 1982. Particular problems of antibiotic use in the elderly. Geriatrics 37(8):49-54.

18. Guthrie B, Clark SA, McCowan C. 2010. The burden of psychotropic drug prescribing in people with dementia: a population database study. Age Ageing 39(5):637-42. http://dx.doi.org/10.1093/ageing/afq090.

19. Hughes LD, Hanslip J, Witham MD. 2012. Centrally active prescribing for nursing home residents - how are we doing? Eur Geriatric Med 3(5):304-7. http://dx.doi.org/10.1016/ j.eurger.2012.04.008.

20. Banerjee S. Report for the minister of state for care services: the use of antipsychotic medication for people with dementia; 2009. Availablefrom: http://www.nhs.uk/news/ 2009/10October/Pages/Antipsychotic-use-in-dementia.aspx [cited 28 October 2012].

21. MacLullich AM, Beaglehole A, Hall RJ, Meagher DJ. 2009. Delirium and long-term cognitive impairment. Int Rev Psychiatry 21(1):30-42. http://dx.doi.org/10.1080/09540260802675031. 22. Himmelheber AM, Sarter M, Bruno JP. 2000. Increases in cortical acetylcholine release during sustained attention performance in rats. Cogn Brain Res 9(3):313-25. http://dx.doi.org/10.1016/S0926-6410(00)00012-4.

23. Ehrenstein G, Galdzicki Z, Lange GD. 1997. The cholineleakage hypothesis for the loss of acetylcholine in Alzheimer's disease. Biophys J 73(3):1276-80. http://dx.doi.org/10.1016/S0006-3495(97)78160-8. 24. Francis PT, Palmer AM, Snape M, Wilcock GK. 1999. The cholinergic hypothesis of Alzheimer's disease: a review of progress. J Neurol Neurosurg Psychiatry 66:137-47. http://dx.doi.org/10.1136/jnnp.66.2.137. 
25. Birks J. Cholinesterase inhibitors for Alzheimer's disease. Cochrane Database Syst Rev; 25(1):CD005593. http://dx.doi.org/10.1002/14651858.CD005593

26. National Institute for Health and Clinical Excellence (2011). Dementia - supporting people with dementia and their carers in health and social care' [incorporating NICE technology appraisal of drugs for Alzheimer's disease]. London: National Institute for Health and Clinical Excellence.

27. Moretti R, Torre P, Antonello RM, Cattaruzza T, Cazzato G. 2004. Cholinesterase inhibition as a possible therapy for delirium in vascular dementia: a controlled, open 24-month study of 246 patients. Am J Alzheimers Dis Other Demen 19(6):333-9. http://dx.doi.org/10.1177/153331750401900607. 28. Oldenbeuving AW, de Kort PL, Jansen BP, Kappelle LJ, Roks G. 2008. A pilot study of rivastigmine in the treatment of delirium after stroke: a safe alternative. BMC Neurol 8:34. http://dx.doi.org/10.1186/1471-2377-8-34.

29. Gamberini M, Bolliger D, Lurati B, Giovanna A, Burkhart $C_{\text {, }}$ Grapow M, et al. 2009. Rivastigmine for the prevention of postoperative delirium in elderly patients undergoing elective cardiac surgery - a randomized controlled trial. Crit Care Med 37:1762-8. http://dx.doi.org/10.1097/CCM.0b013e31819da780. 30. Cerejeira J, Batista P, Nogueira V. 2011. Low preoperative plasma cholinesterase activity as a risk marker of postoperative delirium in elderly patients. Age Ageing 40(5): 621-6. http://dx.doi/org/10.1093/ageing/afr053.

31. van Eijk MMJ, Roes KCB, Honing MLH, Kuiper MA, Karakus $A$, van der Jagt $M$, et al. 2010. Effect of rivastigmine as an adjunct to usual care with haloperidol on duration of delirium and mortality in critically ill patients: a multicentre, double-blind, placebo-controlled randomised trial. Lancet 376:1829-37. http://dx.doi.org/10.1016/S0140-6736(10)61855-7. 32. de Pont AC, van Geer MA, Schultz MJ. 2011. Cholinesterase inhibitor treatment in patients with delirium. Lancet 377(9769):899. http://dx.doi.org/10.1016/S0140-6736(11)60342-5.
33. Frölich L, Förstl H. 2011. Cholinesterase inhibitor treatment in patients with delirium. Lancet 377(9769):899. http:// dx.doi.org/10.1016/S0140-6736(11)60341-3.

34. MacLullich AM, Hall RJ. 2011. Who understands delirium? Age Ageing 40(4):412-4. http://dx.doi.org/10.1093/ageing/afr062. 35. MacLeod AD. 2006. Delirium: the clinical concept. Palliat Support Care 4(3):305-12. http://dx.doi.org/10.1017/ S147895150606038X.

36. British Geriatric Society. Guidelines for the prevention, diagnosis and management of delirium in older people in hospital; 2006. Available from: http://www.bgs.org.uk [cited 28 October 2012].

37. Mason N, Fletcher P. 2012. Assessment of a confused patient. Geriatr Med 42(10):41-5.

38. Maclullich AM, Ferguson KJ, Miller T, de Rooij SE, Cunningham C. 2008. Unravelling the pathophysiology of delirium: a focus on the role of aberrant stress responses. J Psychosom Res 65(3):229-38. http://dx.doi.org/10.1016/ j.jpsychores.2008.05.019.

39. van der Mast RC, Fekkes D. 2000. Serotonin and amino acids: partners in delirium pathophysiology? Semin Clin Neuropsychiatry 5(2):125-31. http://www.ncbi.nlm.nih.gov/ pubmed/10837101.

40. Pandharipande PP, Morandi A, Adams JR, Girard TD, Thompson JL, Shintani AK, et al. 2009. Plasma tryptophan and tyrosine levels are independent risk factors for delirium in critically ill patients. Intensive Care Med 35(11):1886-92. http://dx.doi.org/10.1007/s00134-009-1573-6. 41. Shahid A, Milapkumar $P$, Shagufta J, Rahn KB, Tejas $P$, Marwah S, et al. 2011. Insight into delirium. Innov Clin Neurosci 8(10):25-34. http://www.ncbi.nlm.nih.gov/pmc/ articles/PMC3225129/ 